\title{
Effects of age and Reproductive Status on Tergal Gland Secretions in Queenless Honey bee Workers, Apis mellifera scutellata and A. m. capensis
}

\author{
Olabimpe O. Okosun ${ }^{1,}{ }^{*}$, Abdullahi A. Yusuf ${ }^{1}$, Robin M. Crewe $^{1}$ \\ and Christian W. W. Pirk ${ }^{1}$
}

${ }^{1}$ Social Insects Research Group, Department of Zoology and Entomology, University of Pretoria, Hatfield,
Private Bag X20, 0028 Pretoria, South Africa

Correspondence to: Olabimpe O. Okosun; bimpy@zoology.up.ac.za

\begin{abstract}
Secretions from tergal glands are part of a queen's pheromonal control of worker reproduction in honey bees. However, in queenless honey bee colonies, workers compete to gain pheromonal, and hence reproductive dominance, over nestmates with ontogenetic changes in their glandular secretions that affect the behavioral or physiological responses of other individuals. Using gas chromatography/mass spectrometry, we investigated for the first time the age-dependent changes in tergal gland secretions of queenless workers of the clonal lineage of Apis mellifera capensis and workers of $A$. $m$. scutellata. The reproductive status of honey bee workers was determined by recording the presence of spermathecae and the level of ovarian activation. The tergal gland chemicals identified in both A. $m$. scutellata workers and $A$. $m$. capensis clone workers were oleic acid, $n$-tricosene $n$ pentacosene, and $n$-heptacosene, with three additional compounds, palmitic acid, $n$ heneicosene, and $n$-nonacosene, in $A$. $m$. capensis clones. We report ethyl esters as new compounds from honey bee worker tergal gland profiles; these compounds increased in amount with age. All $A$. $m$. capensis clone workers dissected had spermathecae and showed ovarian activation from day 4 , while ovarian activation only started on day 7 for $A$. $m$. scutellata workers that had no spermathecae. Tergal gland secretions were present in higher quantities in bees with activated, rather than inactive ovaries. This suggests that tergal gland secretions from reproductive workers could act as releaser and primer pheromones in synergy with other glandular compounds to achieve pheromonal and reproductive dominance.
\end{abstract}

\section{Keywords}

Tergal glandsQueenless workersAgeOvarian activationEthyl estersReproductive statusHoney beelnvasive beeSocial parasitism

\section{Introduction}

Pheromones emitted from exocrine glands are involved in chemical communication in insects. These secretions play an important role in maintenance of colony integrity and 
division of labor in social insects (Le Conte and Hefetz 2008). Primer pheromones have longterm effects by altering development, physiology, and neural systems of the receivers, while releaser pheromones have short-term effects that influence a receiver's behavior, including mate attraction, orientation, and alarm in social insects such as ants (Richard and Hunt 2013), termites (Prestwich 1983), bumblebees (Ayasse and Jarau 2014), and honey bees (Pankiw 2004; Winston and Slessor 1998;). A queen uses secretions from her exocrine glands, inclduing mandibular, tergal, or Dufour's, to control the activities and reproductive hierarchy in the colony (Katzav-Gozansky et al. 1997; Keeling et al. 2003; Sole et al. 2002; Winston and Slessor 1998). Not being in direct contact with a queen does not preclude pheromone transfer, as messenger worker bees help to disseminate the queen's pheromones within the colony (Juska et al. 1981; Seeley 1979).

The tergal gland pheromone is an important part of honey bee queen control in a colony. Some of the compounds in the tergal gland secretions of the honey bee include hexadecanoic acid methyl ester (methyl palmitate), (Z)-9-hexadecenoic acid (palmitoleic acid), hexadecanoic acid (palmitic acid), (Z)-9-octadecenoic acid (oleic acid), (E)-11octadecenoic acid (vaccenic acid), octadecanoic acid methyl ester (methyl stearate), octadecanoic acid (stearic acid), decanoic acid (lauric acid), decyl decanoate, $n$-alkanes and alkenes (Al-Qarni et al. 2005; Espelie et al. 1990; Smith et al. 1993; Wossler and Crewe 1999a). A honey bee queen's tergal gland secretions act as contact pheromones that elicit retinue behavior in workers (Wossler and Crewe 1999b). This is achieved in synergy with the mandibular glands' secretions that attract workers for retinue behavior with the help of messenger bees, with the tergal gland secretions helping to maintain the court (Seeley 1979; Velthuis 1985; Vierling and Renner 1977). In some instances, in the absence of mandibular glands, both tergal and Koschewnikow gland secretions are attractive to workers (Butler and Simpson 1965; Vierling and Renner 1977). A queen's tergal gland secretions also are involved in mating behavior, functioning as a source of attractant in mounting drones, initiating fighting among virgin queens, and supressing ovarian activation in workers (Butler 1971; Pflugfelder and Koeniger 2003; Renner and Vierling 1977; Vierling and Renner 1977; Wossler and Crewe 1999c).

Ontogenetic changes in honey bee, Apis mellifera $\mathrm{L}$, queen tergal gland secretions also occur, as well as differences in secretions due to mating status (Al-Qarni et al. 2005; Espelie et al. 1990; Smith et al. 1993; Wossler and Crewe 1999a). Ontogenetic changes in a queen's glandular secretions lead to modulation in both primer and releaser effects on the receiver that can enable the queen to assert her dominance over workers within a colony (Crewe and Velthius 1980; Velthuis 1985). The queen asserts her dominance in the colony through effective regulatory mechanisms in place to maintain the reproductive division of labor (Mohammedi et al. 1998). Nonetheless, some honey bee workers evade reproductive dominance and reproduce, such as in Cape honey bees (Onions 1912; Velthuis 1970; Velthuis et al. 1990).

The Cape honey bee A. m. capensis and the Savannah honey bee, $A$. $m$. scutellata are subspecies found in South Africa. Apis mellifera scutellata is found in the northern region, while $A$. $m$. capensis is found in the Western Cape coastal region. Cape honey bee workers have unique traits, such as thelytokous worker reproduction (Onions 1912), possession of spermathecae (Ruttner 1977), and high ovariole numbers (Phiancharoen et al. 2010). 
Additionally, Cape honey bee workers have short latency periods before becoming reproductive, and produce queen-like pheromones rapidly after queen loss (Crewe and Velthius 1980; Velthuis et al. 1990). The successful reproduction of $A$. m. capensis laying workers in the presence of a queen is possible if they escape the reproductive suppression of the resident queen and brood, and causes reproductive competition that leads to reproductive anarchy (reviewed in Neumann and Hepburn 2002; Neumann and Moritz 2002). All these traits enable A. m. capensis workers to become social parasites in colonies of their own sub-species (Härtel et al. 2006) or other sister sub-species like A. m. scutellata (Neumann and Hepburn 2002; Zheng et al. 2010), despite the presence of queen and worker policing (Neumann et al. 2003; Pirk et al. 2002, 2003).

Since the introduction of an A. m. capensis parasitic lineage (clones) (Baudry et al. 2004) into the native range of $A$. $m$. scutellata in the northern region of South Africa (Allsopp and Crewe 1993; Johannsmeier 1997) by beekeepers, $A$. m. capensis clonal workers have been able to invade queenright $A$. m. scutellata colonies successfully. The infestations of $A . m$. capensis laying worker clones cause annual losses of numerous commercial Savannah honey bee colonies (Du Toit 2001; Johannsmeier 2001). This has forced some commercial beekeepers out of business, resulting in an increase in the price of honey and other bee products as well as the cost of pollination services (Du Toit 2001; Johannsmeier 2001). Furthermore, as a social parasite, $A$. m. capensis clones increase in numbers in $A$. $m$. scutellata colonies upon infestation and, as they do not forage or contribute to the work of the colony, result in eventual death of the infested colony as the number of host workers declines (Neumann and Moritz 2002). In queenless situations, A. m. capensis clones take advantage of the absence of a queen in a colony. This results in strong competition for production of queen-like pheromone bouquets among workers, with some workers becoming reproductive and laying eggs (Crewe and Velthius 1980; Moritz et al. 2000; Velthuis et al. 1990). The success of social parasitism by A. m. capensis laying workers is enhanced by their ability to mimic the queen's mandibular and Dufour's gland secretions (Moritz et al. 2000; Sole et al. 2002).

Queen tergal gland secretions and their roles in the organization of the colony have been extensively investigated (Al-Qarni et al. 2005; Espelie et al. 1990; Renner and Vierling 1977; Smith et al. 1993; Vierling and Renner 1977; Wossler and Crewe 1999a), but little is known about the tergal gland secretions of workers and their role in the colony. Although Wossler and Crewe (1999a) reported that queenright workers of $A$. m. scutellata and A. m. capensis in their native range can be separated, based on tergal gland profile, the tergal gland secretions of queenless workers, and especially those of the A. $m$. capensis parasitic worker clonal lineage, have not been investigated. Moreover, ontogenetic changes and the effects of reproductive status on glandular secretions have been reported for the mandibular gland (Simon et al. 2001, 2005) and Dufour's gland (Sole et al. 2002) of A. m. capensis workers, but not for queenless worker tergal gland secretions or whether these are affected by reproductive status of queenless workers. This study investigated what changes occur in tergal secretions of $A$. $m$. capensis clone workers and $A$. $m$. scutellata workers with age, and whether reproductive status of honey bee workers has an effect on tergal gland secretions. 


\section{Methods and Materials}

\section{Worker Rearing}

Worker brood frames from three colonies were collected from a commercial apiary in Pretoria in November, 2012 for A. m. capensis clones, and from three colonies of $A$. m. scutellata from the University of Pretoria apiary between August 2012 and March 2013. All frames were placed in an incubator at $34{ }^{\circ} \mathrm{C}$ and $60 \%$ r.h until workers emerged. Fifty newly emerged bees from the different colonies then were placed in standard $12.5 \times 10 \times 15 \mathrm{~cm}$ wooden hoarding cages fitted with comb (Pirk et al. 2010) and kept for 2, 4, 6, 7, 14, or 21 days. There were three cages (from the three different colonies) for each day with 21 cages each for A. m. capensis clones and A. m. scutellata. Bees were fed on pollen, $50 \%$ sugar water solution, and water ad libitum.

To compare tergal gland and cuticular profiles of queenless caged honey bee workers with queenright workers, queenright $A$. $m$. scutellata workers were collected from the University of Pretoria apiary (August 2014). Ten honey bee workers of unknown age were collected per colony from three different colonies.

\section{Dissections}

At the end of each trial period $(2,4,6,7,14$, and 21 days), the remaining bees were frozen until required for dissection. Ten bees were randomly selected and dissected for each treatment (day and cage), with a total of 400 bees dissected. The tergal glands of bees at different ages were obtained by dissecting the intersegmental membrane longitudinally with narrow strips of cuticle on both sides from abdominal tergites II-V (Wossler et al. 2000) [mean length (SD) $x$ mean width (SD) $5.34 \pm 0.21 \times 0.51 \pm 0.04 \mathrm{~mm}$ ]. To allow for identification of the tergal gland components, the most anterior portion of abdominal tergite II $(4.06 \pm 0.11 \times 0.67 \pm 0.03 \mathrm{~mm})$ was used to obtain a cuticular extract. These abdominal tergite strips were placed in $100 \mu$ of dichloromethane (DCM) in $2 \mathrm{ml}$ screw top sample vials and stored at $-20^{\circ} \mathrm{C}$ until chemical analysis.

\section{Assessment of Ovary Activation and Presence of Spermatheca}

The level of activation of ovaries in each bee dissected was assessed and ranked following Hess (1942): workers with thread-like ovarioles (stages I-II), workers with intermediate ovaries showing early development of oocytes (stage III), and workers with clearly defined oocytes (stages IV-V) (Hess 1942; Schäfer et al. 2006; Velthuis 1970). For statistical analysis, the ovaries were classified as either inactive (stages I-II) or activated (stages III-V). The presence or absence of spermathecae in the workers also was recorded (Phiancharoen et al. 2010; Ruttner 1977).

\section{Gas Chromatography (GC)}

From the tergal gland and cuticular extracts, an aliquot of $10 \mu \mathrm{l}$ of each was placed in a $150 \mu \mathrm{GC}$ vial insert and evaporated to dryness under a gentle stream of nitrogen; the residue was redissolved in $10 \mu \mathrm{l}$ of internal standard solution ( $1 \mathrm{mg}$ of $n$-hexadecane in $4 \mathrm{ml}$ of DCM) and $10 \mu \mathrm{l}$ of DCM. One microliter of this was injected into an Agilent 
Technology $6890 \mathrm{~N}$ gas chromatograph fitted with an HP5 capillary column (25 $\mathrm{m} \times 0.20 \mathrm{~mm} \times 0.33 \mu \mathrm{m}$; Agilent) and a flame ionization detector (FID). The oven temperature was programmed from 50 to $100^{\circ} \mathrm{C}$ at the maximum heating rate and then ramped to $300{ }^{\circ} \mathrm{C}$ at $6{ }^{\circ} \mathrm{C} \cdot \mathrm{min}^{-1}$, and held for $10 \mathrm{~min}$. The injection port was $230{ }^{\circ} \mathrm{C}$ and the FID $310^{\circ} \mathrm{C}$. Helium was the carrier gas at a flow of $1.0 \mathrm{ml} . \mathrm{min}^{-1}$. Peaks were quantified relative to the internal standard. The amount $(\mu \mathrm{g})$ of each component produced by the tergal gland was obtained by subtracting its amount in the cuticular extract from its amount in the tergal gland extract. Both tergal gland and cuticular compounds were identified based on retentions times in comparison with those of synthetic compounds.

\section{GC-Mass Spectrometry (GC/MS)}

To confirm the identities of the compounds, extracts were analyzed on a Shimadzu QP2010 ultra GC/MS in electron impact ionization mode. One microliter of each sample was injected (at $230^{\circ} \mathrm{C}$ ) with a split ratio of 10:1 onto an InertCap 5MS/NP capillary column (30 $\mathrm{m} \times 0.25 \mathrm{~mm} \times 0.25 \mu \mathrm{m}$; GL Sciences, Tokyo, Japan). Helium was the carrier gas at $1.0 \mathrm{ml} \cdot \mathrm{min}^{-1}$ and the oven was programmed from 50 to $100^{\circ} \mathrm{C}$ at the maximum heating rate and then at $6^{\circ} \mathrm{C} \cdot \mathrm{min}^{-1}$ to $300^{\circ} \mathrm{C}$, and held for $10 \mathrm{~min}$. The ion source was operated at $200^{\circ} \mathrm{C}$. Mass spectral data between $\mathrm{m} / \mathrm{z} 50-700$ were recorded at $70 \mathrm{eV}$ with a scan speed of 2500. Compounds were identified based on a comparison of mass spectra with those in mass spectral libraries [NIST08 and Wiley (10th edition)] and confirmed with pure synthetic fatty acids, alkyl esters, and hydrocarbon standards purchased from Sigma Aldrich (St. Louis, MO, USA).

\section{Statistical Analyses}

Since data for chemical profiles of tergal glands and cuticular extracts were not normally distributed (Shapiro Wilks tests), non-parametric tests were employed (Pirk et al. 2013). The Mann-Whitney $U$ test (MWU) was used to compare honey bee tergal gland and cuticular extracts, as well as honey bee workers with activated and inactive ovaries, for both A. $m$. capensis clones and A. m. scutellata workers. The Kruskal-Wallis test (KWA) was used to compare quantitative changes with age in tergal gland and cuticular extracts for each subspecies. To separate the tergal gland profiles of $A$. m. scutellata workers and A. $m$. capensis clones, the means of the relative proportions of putative semiochemicals were subjected to principal components analysis. All statistical analyses were performed using Statistica 12 (StatSoft USA).

\section{Results}

Chemical Profiles of Tergal Gland and Cuticular Extracts of A. m. capensis Clone Workers and A. m. scutellata Workers

The compounds identified in the tergal gland and cuticle extracts of both $A$. m. capensis clones and $A$. $m$. scutellata workers were fatty acids, alkyl esters, unsaturated ( $n$-alkenes), and saturated hydrocarbons ( $n$-alkanes). 
Unless otherwise specified, MWU values are for differences between tergal gland and cuticular profiles on day 21, and KWA values for differences during adult development. $\ln A$. $m$. capensis clones, for all days, greater quantities of palmitic acid (MWU, $U=125 ; P<0.001$ ) and oleic acid (MWU, $U=56 ; P<0.001$ ) were found in tergal gland, compared to cuticular extract (Supplementary Fig. 1). Similarly, for all days, greater amounts of unsaturated hydrocarbons were found in tergal gland, than in cuticular extracts, for which they were only present in trace amounts: $n$-heneicosene (MWU, $U=72 ; P<0.001$ ), $n$-tricosene (MWU, $U=80 ; P<0.001$ ), $n$-pentacosene (MWU, $U=37 ; P<0.001$ ), $n$-heptacosene (MWU, $U=29$; $P<0.001$ ), and $n$-nonacosene (MWU, $U=70 ; P<0.001$ ) (Supplementary Fig. 2 ). The opposite was true for saturated hydrocarbons, with low amounts in the tergal glands extract compared to the cuticular extract. The amounts of $n$-heptacosane, $n$-nonacosane, and $n$ hentriacontane were greater in cuticular than in tergal gland extracts ( $M W U, U=85$; $P<0.001$ ) (Supplementary Fig. 3).

There were increases in amounts of methyl palmitate [KWA: $\mathrm{H}(6, N=202)=25.77$; $P<0.001$ ], palmitic acid [KWA: $H(6, N=202)=31.54 ; P<0.001$ ], ethyl palmitate [KWA: $H(6$, $N=202)=36.64 ; P<0.001$ ], methyl stearate [KWA: $H(6, N=202)=19.23 ; P<0.001$ ], oleic acid [KWA: $H(6, N=202)=46.49 ; P<0.001$ ], and ethyl oleate [KWA: $H(6, N=202)=30.41$; $P<0.001$ ] (Supplementary Fig. 1) in tergal gland extracts with age. A similar result was found for unsaturated hydrocarbons [KWA: $\mathrm{H}(6, N=202)=28.93 ; P<0.001$ ] (Supplementary Fig. 2), and for saturated hydrocarbons, except for $n$-tricosane [KWA: $\mathrm{H}(6, N=202)=5.32$; $P>0.503$ ] and $n$ - pentacosane [KWA: $\mathrm{H}(6, N=202)=9.55 ; P>0.145$ ] (Supplementary Fig. 3 ).

In the cuticular profiles, there were increases in methyl stearate [KWA: $\mathrm{H}(6$, $N=202)=14.34 ; P=0.026$ ], oleic acid [KWA: $H(6, N=202)=49.42 ; P<0.001$ ], and stearic acid [KWA: $H(6, N=202)=17.18 ; P=0.008$ ] with age (Supplementary Fig. 1). However, there was no increase in amount of unsaturated hydrocarbons with age, except for $n$ pentacosene [KWA: $\mathrm{H}(6, N=202)=31.13 ; P<0.001$ ] (Supplementary Fig. 2). The amounts of $n$-heptacosane [KWA: $\mathrm{H}(6, N=202)=57 ; P<0.001], n$-nonacosane [KWA: $\mathrm{H}(6$, $N=202)=64.88 ; P<0.001$ ], and $n$-hentriacontane [KWA: $\mathrm{H}(6, N=202)=72.07 ; P<0.001$ ] all increased with age (Supplementary Fig. 3).

In A. m. scutellata workers, there were no differences in amounts of fatty acids and alkyl esters between the tergal gland and cuticular extract for most days, except for oleic acid on days 2, 4, 6, 7, and 14 (MWU, $U=191 ; P<0.001$ ) (Supplementary Fig. 4). There were greater amounts of unsaturated hydrocarbons in the tergal gland than in the cuticular extract: $n$ heneicosene (MWU, $U=47 ; P<0.001$ ), $n$-tricosene (MWU, $U=92 ; P<0.001$ ), $n$-pentacosene (MWU, $U=111 ; P<0.001$ ), $n$-heptacosene (MWU, $U=229 ; P<0.001$ ), and $n$-nonacosene on day 7 (MWU, $U=173 ; P<0.001$ ) (Supplementary Fig. 5). There were lower amounts of saturated hydrocarbons in tergal gland extracts than in cuticular extracts (MWU, $U=94$; $P=0.001$ ) (Supplementary Fig. 6), similar to the trend in A. m. capensis clones.

In the tergal gland extracts, there were increases with age in the amounts of methyl palmitate [KWA: $\mathrm{H}(6, N=198)=30.26 ; P<0.001$ ], palmitic acid [KWA: $\mathrm{H}(6$, $N=198)=36.72 ; P<0.001$ ], methyl stearate [KWA: $H(6, N=198)=15.53 ; P=0.017$ ], oleic acid [KWA: $\mathrm{H}(6, N=198)=15.29 ; P=0.018$ ], and ethyl oleate [KWA: $\mathrm{H}(6, N=198)=22.71$; $P<0.001$ ] (Supplementary Fig. 4). For $n$-alkenes, $n$-heneicosene increased and peaked on 
day 21 [KWA: $\mathrm{H}(6, N=198)=17.18 ; P=0.008$ ], while greater amounts of $n$-heptacosene were found on days, 4, 6, and 7 [KWA: $\mathrm{H}(6, N=198)=28.38 ; P=0.008$ ] (Supplementary Fig. 5). Of the $n$-alkanes, only $n$-heptacosane [KWA: $H(6, N=198)=13.12 ; P=0.041], n$ nonacosane [KWA: $\mathrm{H}(6, N=198)=44.29 ; P<0.001$ ], and $n$-hentricontane [KWA: $\mathrm{H}(6$, $N=198)=15.02 ; P=0.020$ ] increased with age in the tergal gland extract (Supplementary Fig. 6).

In the cuticular profiles, there were increases with age in methyl palmitate [KWA: $\mathrm{H}$ (6, $N=198)=25.52 ; P<0.001]$, palmitic acid [KWA: $H(6, N=198)=28.51 ; P<0.001$ ], oleic acid [KWA: $H(6, N=198)=33.83 ; P<0.001]$, and stearic acid [KWA: $H(6, N=198)=24.05$; $P<0.001$ ] (Supplementary Fig. 4). All the unsaturated hydrocarbons, except $n$-heneicosene [KWA: $\mathrm{H}(6, N=198)=18.86 ; P=0.06$ ], increased with age (Supplementary Fig. 5). There were increases with age in the amount of $n$-heptacosane [KWA: $H(6, N=198)=70.81$; $P<0.001$ ],$n$-nonacosane [KWA: $\mathrm{H}(6, N=198)=83.25 ; P<0.001$ ], and $n$-hentricontane [KWA: $\mathrm{H}(6, N=198)=70.52 ; P<0.001$ ]. However, the highest amounts of $n$-heneicosane, $n$ tricosane, and $n$-pentacosane were recorded on day 7 [KWA: $H(6, N=198)=21.46$; $P<0.001$ ] (Supplementary Fig. 6)

Potential semiochemicals from tergal glands of both A. m. scutellata and A. m. capensis clone workers that were different for at least 5 times during development were oleic acid (Supplementary Figs. 1, 4), $n$-tricosene, $n$-pentacosene, and $n$-heptacosene (Supplementary Figs. 2, 5). In A.m. capensis clones, an additional three compounds, palmitic acid (Supplementary Fig. 1), $n$-heneicosene and $n$-nonacosene were greater in tergal glands for all 7 times of development recorded (Supplementary Fig. 2).

The percentage contribution of fatty acid and alkyl esters to the total tergal gland profiles was high for all days, except day 4 for both A.m. capensis clones (Table 1 ) and A. $m$. scutellata workers (Table 1). The percentage contribution of $n$-alkenes to tergal gland profiles was highest on day 6 for both A.m. capensis clones and A. m. scutellata workers (Table 1). The percentage contribution of $n$-alkanes to total cuticular profiles was greatest on day 21 for both A.m. capensis clones and A. m. scutellata workers.

To confirm that the three new compounds found in this study were not artefacts, we sampled honey bee workers from queenright $A$. $m$. scutellata colonies, and we confirmed the presence of the ethyl esters, albeit in low amounts (Table 2). 
Table 1. Relative proportions of compounds in Apis mellifera capensis and A. m. scutellata tergal glands and cuticular extracts on different days

\begin{tabular}{|c|c|c|c|c|c|c|c|c|c|c|c|c|c|c|}
\hline \multicolumn{15}{|c|}{ Age (days), Relative proportions ( \pm SE) } \\
\hline & \multicolumn{2}{|l|}{$0(N=30)$} & \multicolumn{2}{|l|}{$2(N=30)$} & \multicolumn{2}{|l|}{$4(N=30)$} & \multicolumn{2}{|l|}{$6(N=29)$} & \multicolumn{2}{|l|}{$7(N=29)$} & \multicolumn{2}{|l|}{$14(N=26)$} & \multicolumn{2}{|l|}{$21(N=24)$} \\
\hline & \begin{tabular}{|l}
$\begin{array}{l}\text { Tergal } \\
\text { gland }\end{array}$ \\
\end{tabular} & \begin{tabular}{|l}
$\begin{array}{l}\text { Cuticular } \\
\text { profile }\end{array}$ \\
\end{tabular} & $\begin{array}{l}\begin{array}{l}\text { Tergal } \\
\text { gland }\end{array} \\
\end{array}$ & $\begin{array}{l}\begin{array}{l}\text { Cuticular } \\
\text { profile }\end{array} \\
\end{array}$ & $\begin{array}{l}\text { Tergal } \\
\text { gland }\end{array}$ & \begin{tabular}{|l}
$\begin{array}{l}\text { Cuticular } \\
\text { profile }\end{array}$ \\
\end{tabular} & \begin{tabular}{|l}
$\begin{array}{l}\text { Tergal } \\
\text { gland }\end{array}$ \\
\end{tabular} & \begin{tabular}{|l}
$\begin{array}{l}\text { Cuticular } \\
\text { profile }\end{array}$ \\
\end{tabular} & $\begin{array}{l}\begin{array}{l}\text { Tergal } \\
\text { gland }\end{array} \\
\end{array}$ & \begin{tabular}{|l}
$\begin{array}{l}\text { Cuticular } \\
\text { profile }\end{array}$ \\
\end{tabular} & $\begin{array}{l}\begin{array}{l}\text { Tergal } \\
\text { gland }\end{array} \\
\end{array}$ & \begin{tabular}{|l|}
$\begin{array}{l}\text { Cuticular } \\
\text { profile }\end{array}$ \\
\end{tabular} & $\begin{array}{l}\text { Tergal } \\
\text { gland }\end{array}$ & \begin{tabular}{|l|}
$\begin{array}{l}\text { Cuticular } \\
\text { profile }\end{array}$ \\
\end{tabular} \\
\hline \multicolumn{15}{|c|}{ A. m. capensis } \\
\hline \begin{tabular}{|l|}
\multicolumn{1}{|c|}{ Fatty } \\
acids \\
and \\
esters \\
\end{tabular} & $50.74 \pm 1.51$ & $53.60 \pm 1.46$ & $45.42 \pm 1.52$ & $|48.59 \pm 1.00|$ & $37.34 \pm 1.25$ & $\mid 42.37 \pm 1.22$ & $40.97 \pm 0.96$ & $42.82 \pm 1.15$ & $\mid 49.73 \pm 1.06$ & $37.80 \pm 1.06$ & $\mid 45.84 \pm 1.27$ & $39.94 \pm 1.04$ & $45.49 \pm 1.11 \mid$ & $32.15 \pm 0.88$ \\
\hline \begin{tabular}{|c|}
$n-$ \\
alkenes \\
\end{tabular} & $17.5 \pm 0.35$ & $7.05 \pm 0.14$ & $\mid 26.01 \pm 1.17$ & $9.96 \pm 0.71$ & $22.19 \pm 0.46$ & $7.63 \pm 0.28$ & $32.03 \pm 0.38$ & $8.44 \pm 0.27$ & $15.3 \pm 0.30$ & $3.82 \pm 0.39$ & $25.44 \pm 1.37$ & $1.34 \pm 0.02$ & $|23.39 \pm 0.83|$ & $4.92 \pm 0.27$ \\
\hline \begin{tabular}{|c|}
$n-$ \\
alkanes \\
\end{tabular} & $31.76 \pm 0.97$ & $39.34 \pm 0.77$ & $\mid 28.58 \pm 1.47$ & $\| 41.45 \pm 0.87$ & $40.46 \pm 0.80$ & $49.99 \pm 0.75$ & $27.00 \pm 0.61$ & $48.73 \pm 0.80$ & || $35.08 \pm 0.97 \mid$ & $58.38 \pm 1.33$ & $\mid 27.81 \pm 1.03$ & $61.73 \pm 2.40$ & $|31.12 \pm 0.66|$ & $62.94 \pm 2.62$ \\
\hline \multicolumn{15}{|c|}{ A. m. scutellata } \\
\hline \begin{tabular}{|l|}
\multicolumn{1}{|c|}{ Fatty } \\
acids \\
and \\
esters \\
\end{tabular} & $48.16 \pm 1.22$ & $50.49 \pm 1.20$ & $48.49 \pm 1.19$ & $\| 49.93 \pm 1.16$ & $41.11 \pm 1.11$ & $46.91 \pm 1.60$ & $42.20 \pm 0.96$ & $44.36 \pm 1.20$ & ||43.91 41.27 & $44.04 \pm 1.50$ & $54.14 \pm 1.05$ & $50.08 \pm 1.32$ & $45.04 \pm 0.79$ & $31.05 \pm 0.54$ \\
\hline \begin{tabular}{|c|}
$n-$ \\
alkenes
\end{tabular} & $18.62 \pm 0.57$ & $10.54 \pm 1.26$ & $17.32 \pm 0.38$ & $9.46 \pm 0.50$ & $14.37 \pm 0.31$ & $5.38 \pm 0.45$ & $18.8 \pm 0.56$ & $4.79 \pm 0.73$ & $18.03 \pm 0.53$ & $2.69 \pm 0.12$ & $14.73 \pm 0.39$ & $8.02 \pm 0.30$ & $\mid 18.35 \pm 0.24$ & $12.63 \pm 1.59$ \\
\hline \begin{tabular}{|c|}
$n-$ \\
alkanes
\end{tabular} & $33.21 \pm 1.08$ & $5.38 .97 \pm 1.07$ & $37.18 \pm 1.34$ & $40.61 \pm 1.01$ & $44.43 \pm 1.01$ & $47.70 \pm 1.26$ & $39.00 \pm 1.14$ & $50.85 \pm 1.45$ & $38.05 \pm 1.33$ & $52.33 \pm 1.05$ & $31.13 \pm 0.84$ & $41.90 \pm 0.99$ & $36.61 \pm 0.81$ & $56.33 \pm 2.90$ \\
\hline
\end{tabular}


Table 2. The amounts of compounds ( $\mu \mathrm{g} \pm \mathrm{SE}$ ) in tergal gland and cuticular extracts of Apis mellifera scutellata queen right workers

\begin{tabular}{|c|c|c|}
\hline Compounds & Tergal gland $(N=30)$ & Cuticular profile $(N=30)$ \\
\hline \multicolumn{3}{|l|}{ Fatty acids and esters } \\
\hline Methyl palmitate & $0.07 \pm 0.02$ & $0.09 \pm 0.01$ \\
\hline Palmitic acid & $0.05 \pm 0.01$ & $0.02 \pm 0.004$ \\
\hline Ethyl palmitate & $0.10 \pm 0.03$ & $0.04 \pm 0.01$ \\
\hline Methyl stearate & $0.15 \pm 0.04$ & $0.09 \pm 0.02$ \\
\hline Oleic acid & $0.06 \pm 0.01$ & $0.02 \pm 0.01$ \\
\hline Stearic acid & $0.19 \pm 0.05$ & $0.10 \pm 0.03$ \\
\hline Ethyl oleate & $0.07 \pm 0.03$ & $0.01 \pm 0.04$ \\
\hline Ethyl stearate & $0.13 \pm 0.04$ & $0.12 \pm 0.02$ \\
\hline \multicolumn{3}{|l|}{$n$-alkenes } \\
\hline Heneicosene & $0.08 \pm 0.02$ & $0.03 \pm 0.01$ \\
\hline Tricosene & $0.16 \pm 0.05$ & $0.01 \pm 0.002$ \\
\hline Pentacosene & $0.15 \pm 0.04$ & $0.03 \pm 0.01$ \\
\hline Heptacosene & $0.09 \pm 0.03$ & $0.01 \pm 0.003$ \\
\hline Nonacosene & $0.07 \pm 0.02$ & $0.01 \pm 0.01$ \\
\hline \multicolumn{3}{|l|}{$n$-alkanes } \\
\hline Heneicosane & $0.03 \pm 0.01$ & $0.03 \pm 0.003$ \\
\hline Tricosane & $0.20 \pm 0.04$ & $0.24 \pm 0.03$ \\
\hline Pentacosane & $0.15 \pm 0.05$ & $0.16 \pm 0.01$ \\
\hline Heptacosane & $0.11 \pm 0.10$ & $0.14 \pm 0.02$ \\
\hline Nonacosane & $0.09 \pm 0.04$ & $0.06 \pm 0.01$ \\
\hline Hentricontane & $0.08 \pm 0.03$ & $0.05 \pm 0.01$ \\
\hline
\end{tabular}

\section{Assessment of Ovary Activation and Presence of Spermathecae}

Of the 400 bees dissected ( $A$. $m$. capensis clones $N=202, A$. $m$. scutellata workers $N=198$ ), all $A$. $m$. capensis clones had spermathecae present, but none of the $A$. $m$. scutellata workers did. We used the presence of spermathecae in $A$. m. capensis workers to confirm that they were clones. In $A$. m. capensis clone workers, activation of the ovaries started as early as day 4 , while in A. m. scutellata activation started only on day 7 (Supplementary Fig. 7).

Tergal Gland Compounds and Ovarial Status of A. m. capensis Clones and A. m. scutellata

In $A$. m. capensis clones and $A$. $m$. scutellata, there were differences (MWU, $U=12 ; P$ $<0.001$ ) between honey bee workers with activated and inactive ovaries for all the tergal gland fatty acids and esters (Supplementary Fig. 7A, B), unsaturated hydrocarbons (Supplementary Fig. 7C, D), and saturated hydrocarbons (Supplementary Fig. 7E, F).

The principal component analysis of $A$. m. capensis clones and $A$. m. scutellata workers with activated or inactive ovaries is shown in Fig. 1. Apis mellifera capensis clones and A. $m$. 
scutellata workers could be separated based on age, ovarian activation and subspecies. Oleic acid and $n$-heptacosene had factor loadings greater than 0.5 for the first component, and described $25.23 \%$ of the variation, while the second factor described $23.64 \%$ of the variation with high loadings for $n$-tricosene.

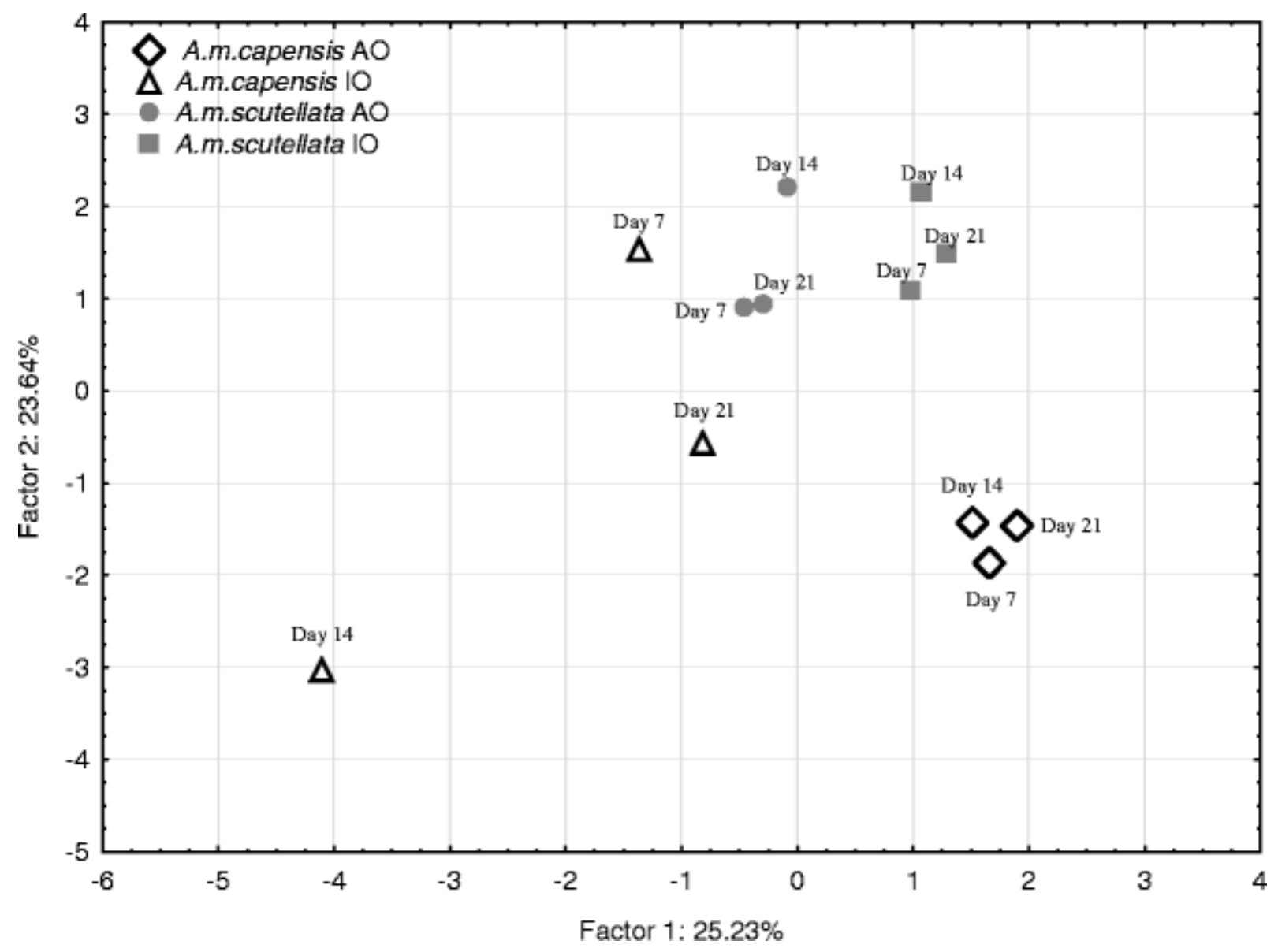

Fig. 1. Separation by principal component analysis, of potential tergal gland semiochemicals of Apis mellifera capensis clones and A. m. scutellata workers (days 7, 14, and 21) with activated ovaries (AO) and inactive ovaries (IO)

\section{Discussion}

Tergal gland profiles of $A$. m. capensis clones were distinctive from those of $A$. m. scutellata workers. The compounds identified were mostly fatty acids, alkenes, and alkyl esters. Both A. $m$. scutellata and $A$. $m$. capensis clones contained oleic acid, $n$-tricosene, $n$-pentacosene, and $n$-heptacosene, while an additional three compounds, palmitic acid, $n$-heneicosene, and $n$-nonacosene, were found in A. $m$. capensis clones. These compounds increased with age for queenless caged workers of both sub-species.

All compounds found in this study, except for the three ethyl esters, ethyl palmitate, ethyl oleate, and ethyl stearate, have been reported previously in tergal gland profiles of virgin, mated queens and queenright workers of both $A$. m. capensis and A. m. scutellata (Wossler and Crewe 1999a). The ethyl esters have been reported as part of honey bee brood pheromone (Le Conte et al. 1990). Since workers were kept in cages without brood, we can exclude contamination as the source of these compounds. Traces of ethyl oleate have been 
found on honey bee worker cuticle (Leoncini et al. 2004), while ethyl palmitate and ethyl oleate have been found on the cuticle of stingless bees Frieseomelitta vari (Nunes et al. 2008). Ethyl palmitate has been implicated in inhibition of ovary activation in honey bee workers (Mohammedi et al. 1998), while ethyl oleate delays transition of nurse honey bees into foragers (Castillo et al. 2012). The latter causes nurse bees to spend more time in the hive to tend to the brood and the queen (Leoncini et al. 2004). Since reproductively dominant bees need more subordinate individuals to tend to their needs (Hillesheim et al. 1989), one would expect that the signal for dominance should be more abundant in bees with activated ovaries. Thus, the greater amounts of these ethyl esters in the tergal gland of reproductive workers is consistent with their role as primer pheromones that suppress ovarian activation of their nestmates, thus achieving reproductive dominance over other workers in queenless situations.

Fatty acids and esters are most abundant in the tergal gland extracts of $A$. mellifera scutellata and A. m. capensis queenright workers (Wossler and Crewe 1999a). Similarly, here, fatty acid and alkyl esters were most abundant in the tergal gland extracts, on all days sampled, of caged queenless workers for both $A$. m. capensis clones and A. m. scutellata. In honey bees, mated queens have larger amounts of fatty acids and esters in their tergal gland compared to virgin queens (Espelie et al. 1990; Wossler and Crewe 1999a). Additionally, Al-Qarni et al. (2005) have reported that palmitoleic, palmitic, and oleic acids were present in greater quantities in naturally mated queens than in artificially inseminated ones. We found a similar trend with reproductive status of queenless workers: palmitic and oleic acids were present in greater quantities in ovary-activated workers than in nonreproductive workers. As honey bees with activated ovaries have more tergal gland compounds than non-reproductively active bees, this suggests that these fatty acids work with secretions from other glands to achieve pheromonal and reproductive dominance among queenless workers.

Alkenes also are abundant in the tergal gland extracts of $A$. m. scutellata and A. m. capensis queenright (Wossler and Crewe 1999a) and queenless workers (our study). Reproductive status and age are known to affect tergal gland secretions of honey bee queens (Smith et al. 1993). Similarly, we found increases in the amount of tergal gland alkenes with regard to reproductive status and age for both $A$. $m$. capensis worker clones and A. $m$. scutellata workers. This suggests that tergal gland alkenes play a role in establishing pheromonal dominance of reproductively active honey bee workers in the colony.

Clone workers of $A$. m. capensis have the ability to achieve reproductive dominance as they increase in numbers and take over host colonies (Neumann and Moritz 2002), but do not participate in standard hive duties (Hillesheim et al. 1989), and they have high ovariole numbers and spermathecae (Phiancharoen et al. 2010). Thus, the presence of spermathecae in all $A$. m. capensis workers in this study confirms that they are A. m. capensis workers. Additionally, initiation of ovarian activation as early as day 4 in $A$. m. capensis clones, the presence of spermatheca in all clones, and the higher percentage of bees with activated ovaries compared to $A$. $m$. scutellata workers, could aid $A$. $m$. capensis clones in achieving complete reproductive dominance when the host queen is lost during host colony infestation. 
The role of the identified compounds, in particular the three new esters, in regulating social interactions among workers will be explored using behavioral bioassays.

\section{Acknowledgments}

The authors thank Kendall Crous and Ursula Strauss for helping with sampling, and the beekeeper that provided $A$. $m$. capensis clones. This research was supported by a University of Pretoria postgraduate research bursary (Okosun), by the Competitive Programme for Rated Researcher of the National Research Foundation (NRF) South Africa (Pirk), incentive funding of the NRF (Crewe, Pirk), and the DST/NRF SARChl Chair in Mathematical Models and Methods in Bioengineering and Biosciences (M3B2) at the University of Pretoria (Yusuf).

\section{References}

Allsopp MH, Crewe RM (1993) The Cape Honey bee as a Trojan Horse rather than the hordes of Genghis Khan. Am Bee J 133:121-123

Al-Qarni A, Phelan P, Smith B, Cobey S (2005) Tergal glandular secretions of naturally mated and instrumentally inseminated honey bee queens (Apis mellifera L.). J King Saud Univ 17:125-137

Ayasse M, Jarau S (2014) Chemical ecology of bumble bees. Annu Rev Entomol 59:299-319

Baudry E, Kryger P, Allsopp MH, Koeniger N, Vautrin D, Mougel F, Cornuet J-M, Solignac M (2004) Whole-genome scan in thelytokous-laying workers of the cape honey bee (Apis mellifera capensis): central fusion, reduced recombination rates and centromere mapping using half-tetrad analysis. Genetics 167:243-252

Butler CG (1971) The mating behaviour of the honey bee. (Apis mellifera L). J Entomol A 46:1-11

Butler CG, Simpson J (1965) Pheromones of the honey bee. An olfactory pheromone from the Koschewnikow gland of the queen. Univ Libcice Sci Stud 4:33-36

Castillo C, Chen H, Graves C, Maisonnasse A, Le Conte Y, Plettner E (2012) Biosynthesis of ethyl oleate, a primer pheromone, in the honeybee (Apis mellifera L.). Insect Biochem Mol Biol 42:404416

Crewe RM, Velthius HHW (1980) False queens: a consequence of mandibular gland signals in worker honey bees. Naturwissenschaften 67:467-469

Du Toit AP (2001) The South Africa Beekeeping industry. South Afr Bee J 73:161-165

Espelie KE, Butz VM, Dietz A (1990) Decyl decanoate: a major component of the tergite glands of honey bee queens (apis mellifera L). J Apic Res 29:15-19

Härtel S, Neumann P, Raassen FS, Moritz RFA, Hepburn HR (2006) Social parasitism by Cape honeybee workers in colonies of their own subspecies (Apis mellifera capensis Esch.). Insect Soc 53:183-193

Hess G (1942) Uber die Einfluss der Weisellosigheit und des Fruchtbarkeits-vitamins E auf die Ovarien der Bienearbeiterin. Beih zur Schweiz Bienen-Ztg 1:33-109 
Hillesheim E, Koeniger N, Moritz RFA (1989) Colony performance in honey bees (Apis mellifera capensis Esch.) depends on the proportion of subordinate and dominant workers. Behav Ecol Sociobiol 24:291-296

Johannsmeier MF (1997) Overcoming the capensis problem. South Afr Bee J 69:63-70

Johannsmeier MF (2001) Bee keeping history. In: Johannsmeier MF (ed) Bee keeping in South Africa. Plant protection handbook No. 14. Agricultural research Council, Pretoria, p 288

Juska A, Seeley TD, Velthuis HHW (1981) How honey bee queen attendants become ordinary workers. J Insect Physiol 27:515-519

Katzav-Gozansky T, Soroker V, Hefetz A (1997) Plasticity of caste-specific Dufour's gland secretion in the honey bee (Apis mellifera L.). Naturwissenschaften 84:238-241

Keeling Cl, Slessor KN, Higo HA, Winston ML (2003) New components of the honey bee (Apis mellifera L.) queen retinue pheromone. Proc Natl Acad Sci U S A 100:4486-4491

Le Conte Y, Hefetz A (2008) Primer pheromones in social Hymenoptera. Annu Rev Entomol 53:523542

Le Conte Y, Arnold G, Trouiller J, Masson C (1990) Identification of a brood pheromone in honey bees. Naturwissenschaften 77:334-336

Leoncini I, Le Conte Y, Costagliola G, Plettner E, Toth AL, Wang W, Huang Z, Becard J, Crauser D, Slessor KN, Robinson GE (2004) Regulation of behavioral maturation by a primer pheromone produced by adult worker honey bees. Proc Natl Acad Sci U S A 101:17559-17564

Mohammedi AP, Crauser D, Le Conte Y (1998) Effect of aliphatic esters on ovary development of queenless bees (Apis mellifera L.). Naturwissenschaften 85:455-458

Moritz RFA, Simon UE, Crewe RM (2000) Pheromonal contest between honey bee workers (Apis mellifera capensis). Naturwissenschaften 87:395-397

Neumann P, Hepburn R (2002) Behavioural basis for social parasitism of Cape honey bees (Apis mellifera capensis). Apidologie 33:165-192

Neumann P, Moritz RFA (2002) The Cape honey bee phenomenon: the evolution of a social parasite in real time? Behav Ecol Sociobiol 52:271-281

Neumann P, Pirk CWW, Hepburn HR, Moritz RFA (2003) Spatial differences in worker policing facilitate social parasitism of Cape honey bee workers (Apis mellifera capensis Esch.) in queenright host colonies. Insect Soc 50:109-112

Nunes TM, Nascimento FS, Turatti IC, Lopes NP, Zucchi R (2008) Nestmate recognition in a stingless bee: does the similarity of chemical cues determine guard acceptance? Anim Behav 75:1165-1171

Onions GW (1912) South African "fertile worker bees.". Agric J Union S Afr 3:720-728 
Pankiw T (2004) Cued in: honey bee pheromones as information flow and collective decision-making. Apidologie 35:217-226

Pflugfelder J, Koeniger N (2003) Fight between virgin queens (Apis mellifera) is initiated by contact to the dorsal abdominal surface. Apidologie 34:249-256

Phiancharoen M, Pirk CWW, Radloff SE, Hepburn R (2010) Clinal nature of the frequencies of ovarioles and spermathecae in Cape worker honey bees, Apis mellifera capensis. Apidologie 41:129134

Pirk CWW, Neumann P, Hepburn HR (2002) Egg laying and egg removal by workers are positively correlated in queenright Cape honey bee colonies (Apis mellifera capensis). Apidologie 33:203-211

Pirk CWW, Neumann P, Ratnieks FLW (2003) Cape honey bees, Apis mellifera capensis, police worker-laid eggs despite the absence of relatedness benefits. Behav Ecol 14:347-352

Pirk CWW, Boodhoo C, Human H, Nicolson SW (2010) The importance of protein type and protein to carbohydrate ratio for survival and ovarian activation of caged honeybees (Apis mellifera scutellata). Apidologie 41:62-72

Pirk CWW, de Miranda JR, Kramer M, Murray TE, Nazzi F, Shutler D, van der Steen JJM, van Dooremalen C (2013) Statistical guidelines for Apis mellifera research. J Apic Res 52:1-24. doi:10.3896/IBRA.1.52.4.13

Prestwich GD (1983) Chemical systematics of termite exocrine secretions. Annu Rev Ecol Syst 14:287-311

Renner M, Vierling G (1977) The secretion of the tergite glands and the attractiveness of the queen honey bee to drones in the mating flight. Behav Ecol Sociobiol 2:329-338

Richard FJ, Hunt JH (2013) Intracolony chemical communication in social insects. Insect Soc 60:275291

Ruttner $\mathrm{F}$ (1977) The problem of the Cape bee (Apis mellifera capensis Escholtz): parthenogenesissize of population-evolution. Apidologie 8:281-294

Schäfer MO, Dietemann V, Pirk CWW, Neumann P, Crewe RM, Hepburn HR, Tautz J, Crailsheim K (2006) Individual versus social pathway to honey bee worker reproduction (Apis mellifera): pollen or jelly as protein source for oogenesis? J Comp Physiol A 192:761-768

Seeley TD (1979) Queen substance dispersal by messenger workers in honey bee colonies. Behav Ecol Sociobiol 5:391-415

Simon UE, Moritz FA, Crewe RM (2001) The ontogenetic pattern of mandibular gland components in queenless workers bees (Apis mellifera capensis Esch). J Insect Physiol 47:735-738

Simon UE, Moritz FA, Crewe RM (2005) Reproductive dominance among honeybee workers in experimental groups of Apis mellifera capensis. Apidologie 36:413-419

Smith R, Spivak M, Taylor OR, Bennet C, Smith ML (1993) Maturation of tergal gland alkenes profiles in European honey bee queens, Apis mellifera L. J Chem Ecol 19:133-141 
Sole CL, Kryger P, Hefetz A, Katzav-Gozansky T, Crewe RM (2002) Mimicry of queen Dufour's gland secretions by workers of Apis mellifera scutellata and A. m. capensis. Naturwissenschaften 89:561564

Velthuis HHW (1970) Ovarian development in Apis mellifera worker bees. Entomol Exp Appl 13(377):394

Velthuis HHW (1985) The honey bee queen and the social organization of her colony. In: Holldobler B, Lindauer M (eds) Experimental behavioural ecology. G. Fischer Verlag, New York, pp 343-357

Velthuis HHW, Ruttner F, Crewe RM (1990) Differentiation in reproductive physiology and behaviour during the development of laying worker honey bees. In: Engels W (ed) Social insects. SpringerVerlag, Berlin, pp 231-243

Vierling G, Renner M (1977) The secretion of the tergite glands and the attractiveness of the honey bee queen. Behav Ecol Sociobiol 2:185-200

Winston ML, Slessor KN (1998) Honey bee primer pheromones and colony organization: gaps in our knowledge. Apidologie 29:81-95

Wossler TC, Crewe RM (1999a) Mass spectral identification of the tergal gland secretions of female castes of two African honey bee races (Apis mellifera). J Apic Res 38:137-148

Wossler TC, Crewe RM (1999b) The releaser effects of the tergal gland secretion of queen honey bees (Apis mellifera). J Insect Behav 12:343-351

Wossler TC, Crewe RM (1999c) Honey bee queen tergal secretion affects ovarian development in caged workers. Apidologie 30:311-320

Wossler TC, Veale RM, Crewe RM (2000) How queen-like are the tergal glands in workers of Apis mellifera capensis and Apis mellifera scutellata? Apidologie 31:47-54

Zheng HQ, Dietemann V, Crewe RM, Hepburn HR, Hu FL, Yang MX, Pirk CWW (2010) Pheromonal predisposition to social parasitism in the honey bee Apis mellifera capensis. Behav Ecol 21:12211226 


\section{Supplementary material}

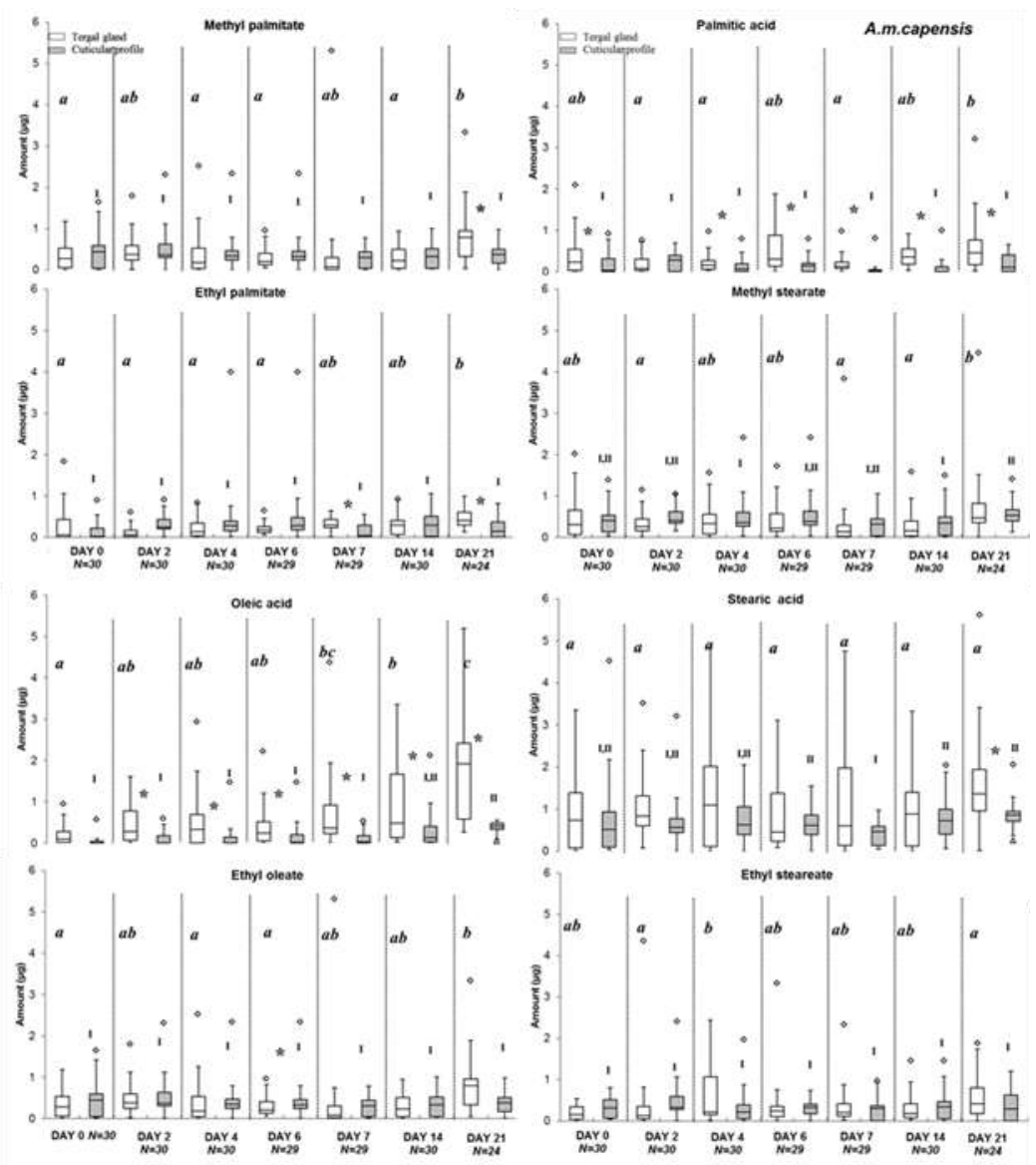

Figure 1. The amounts of fatty acids and esters in tergal gland and cuticular profiles of Apis $m$. capensis clones (days $0,2,4,6,7,14$, and 21, $N=202$ ). The median line, quartile, whisker, minifum $\diamond_{\text {and }}$ maximum outliers are shown. * denotes significant difference at $P<0.05$ (Mann -Whitney $U$ test) of the pairwise comparison between tergal gland and cuticular profile for each day. Different letters within the row represent significant differences at $P<0.05$ (Kruskal Wallis-test) on different days for tergal gland profile. Different roman numerals within the row represent significant differences at $P<0.05$ (Kruskal Wallis-test) on different days for cuticular profile 

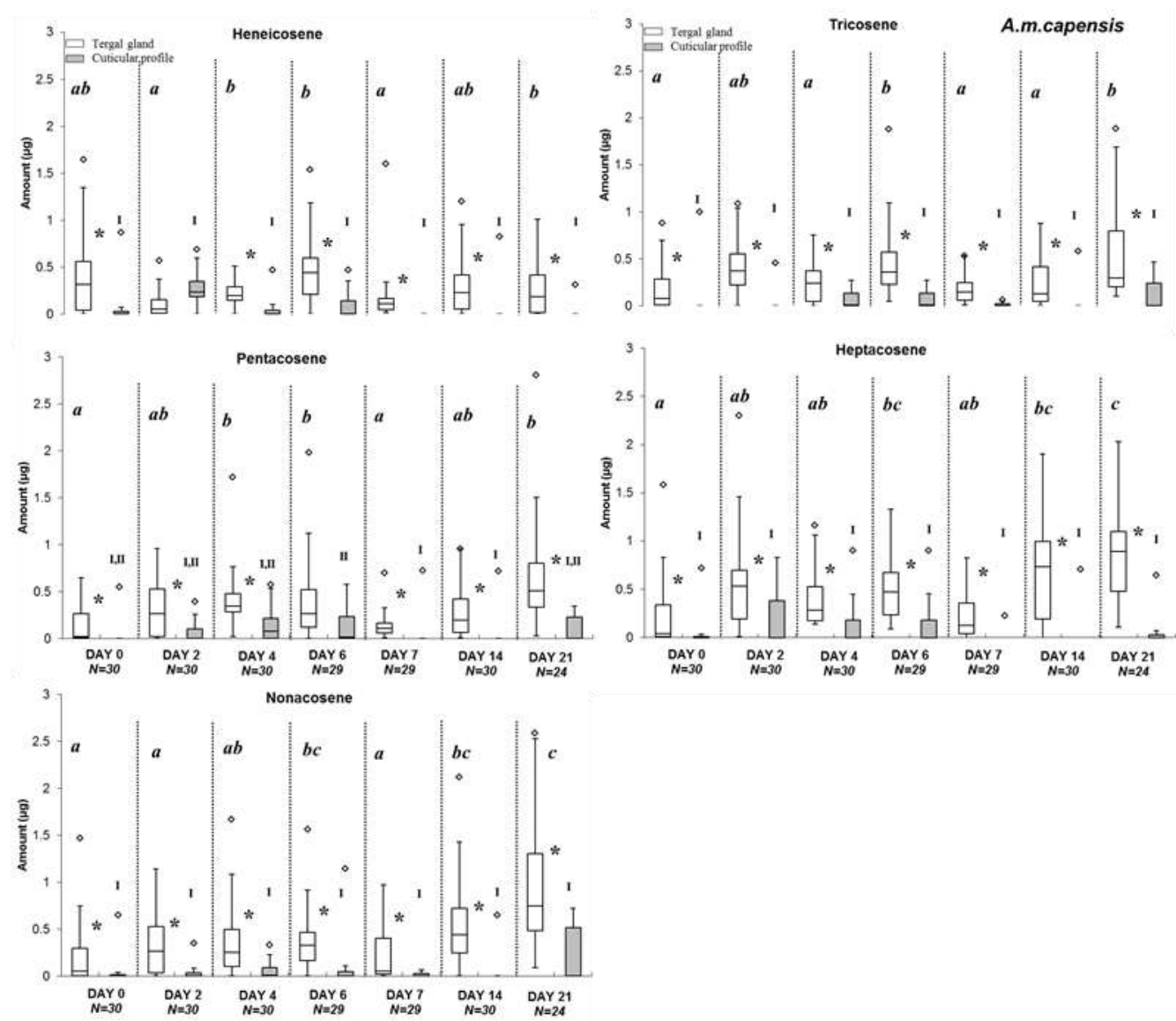

Figure 2. The amounts of $n$-alkenes in tergal gland and cuticular profiles of Apis m. capensis clones (days 0,2 , $4,6,7,14$, and 21, $N=202$ ). The median line, quartile, whisker, miAnmum and maX̂mum outliers are shown. * denotes significant difference at $P<0.05$ (Mann -Whitney $U$ test) of the pairwise comparison between tergal gland and cuticular profile for each day. Different letters within the row represent significant differences at $P<$ 0.05 (Kruskal Wallis-test) on different days for tergal gland profile. Different roman numerals within the row represent significant differences at $P<0.05$ (Kruskal Wallis-test) on different days for cuticular profile 

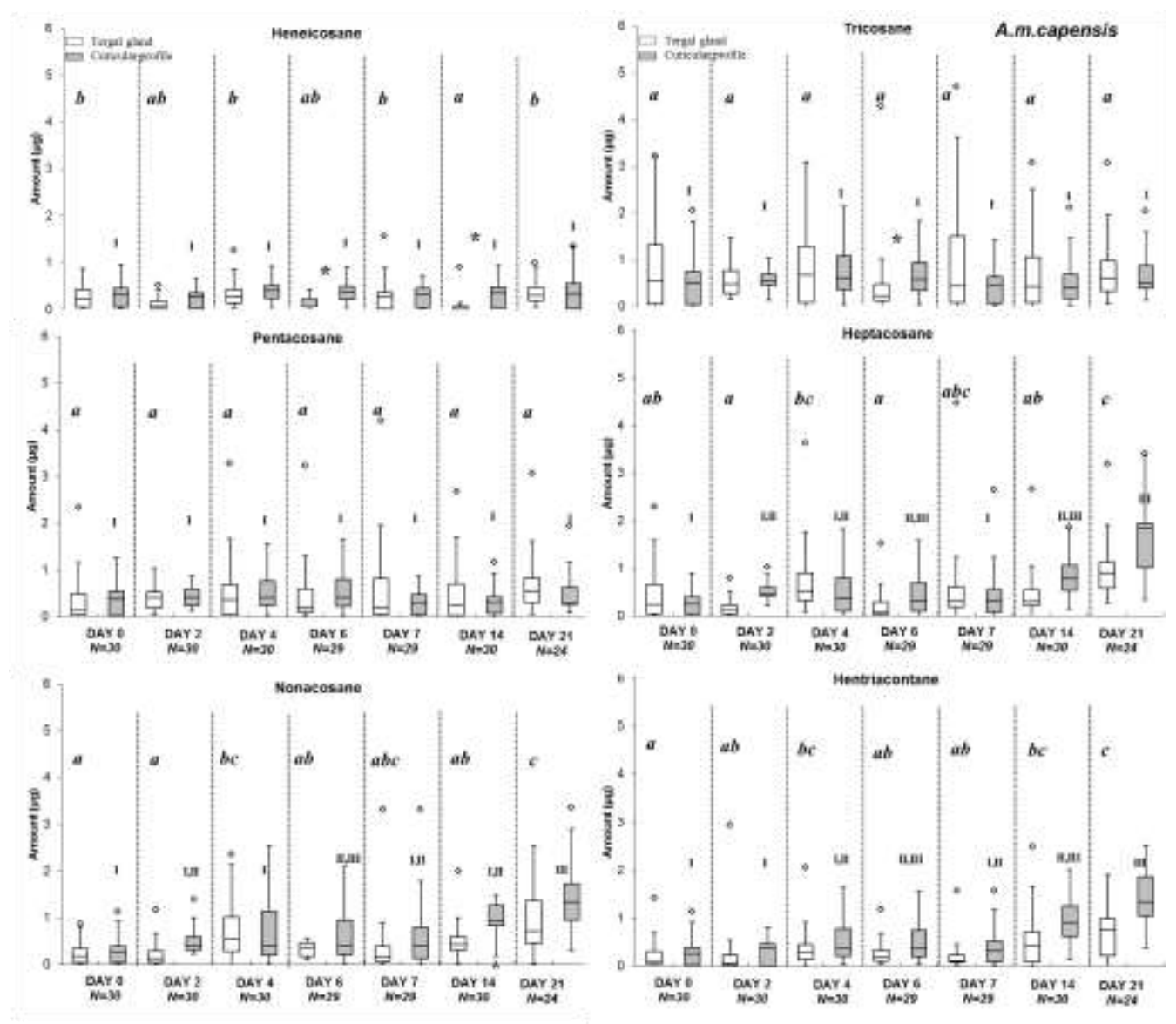

Figure 3. The amounts of $n$-alkanes in tergal gland and cuticular profiles of Apis m. capensis clones (days 0,2 , $4,6,7,14$, and 21, $N=202$ ). The median line, quartile, whisker, mi Anmum and maर̂mum outliers are shown. * denotes significant difference at $P<0.05$ (Mann -Whitney $U$ test) of the pairwise comparison between tergal gland and cuticular profile for each day. Different letters within the row represent significant differences at $P<$ 0.05 (Kruskal Wallis-test) on different days for tergal gland profile. Different roman numerals within the row represent significant differences at $P<0.05$ (Kruskal Wallis-test) on different days for cuticular profile 


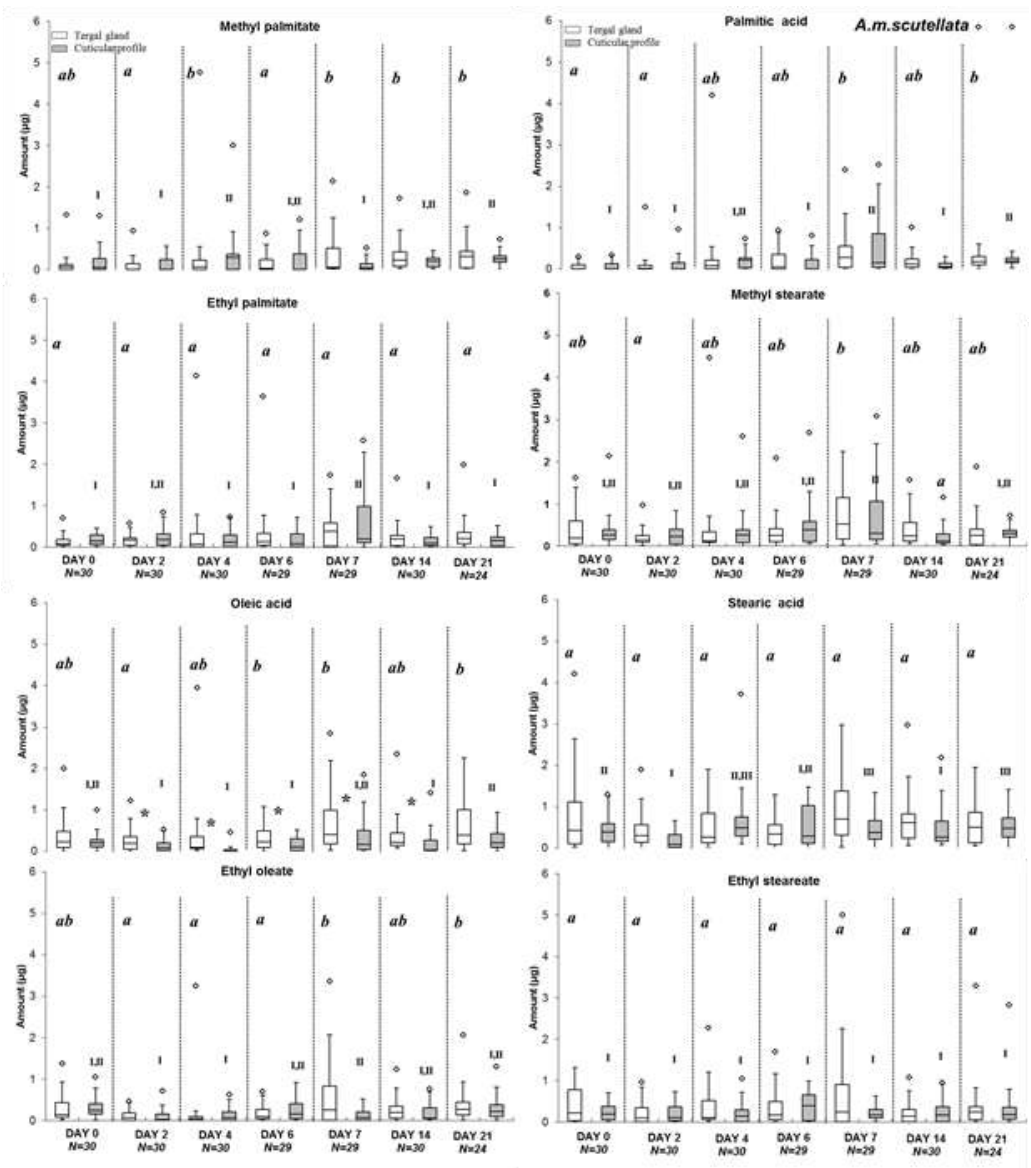

Figure 4. The amounts of fatty acids and esters in tergal gland and cuticular profiles of Apis m. scutellata workers (days $0,2,4,6,7,14$, and 21, $N=198$ ). The median line, quartile, whisker, mAimum and moximum outliers are shown. ${ }^{*}$ denotes significant difference at $P<0.05$ (Mann -Whitney $U$ test) of the pairwise comparison between tergal gland and cuticular profile for each day. Different letters within the row represent significant differences at $P<0.05$ (Kruskal Wallis-test) on different days for tergal gland profile. Different roman numerals within the row represent significant differences at $P<0.05$ (Kruskal Wallis-test) on different days for cuticular profile 

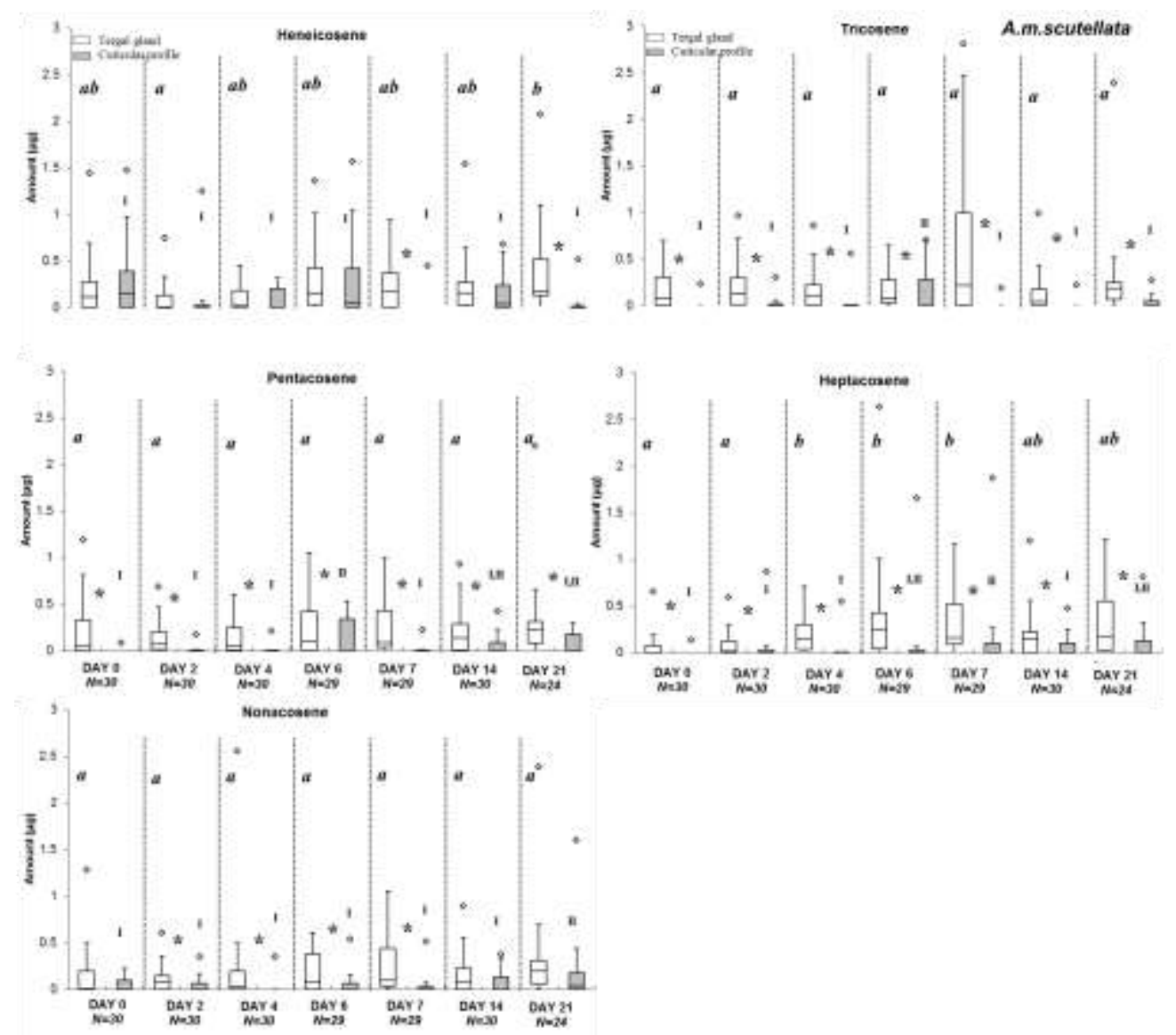

Figure 5. The amounts of $n$-alkenes in tergal gland and cuticular profiles of Apis m. scutellata workers (days 0 , $2,4,6,7,14$, and 21, $N=198$ ). The median line, quartile, whisker, mininum and maxirpum outliers are shown. ${ }^{*}$ denotes significant difference at $P<0.05$ (Mann -Whitney $U$ test) of the pairwise comparison between tergal gland and cuticular profile for each day. Different letters within the row represent significant differences at $P<0.05$ (Kruskal Wallis-test) on different days for tergal gland profile. Different roman numerals within the row represent significant differences at $P<0.05$ (Kruskal Wallis-test) on different days for cuticular profile 

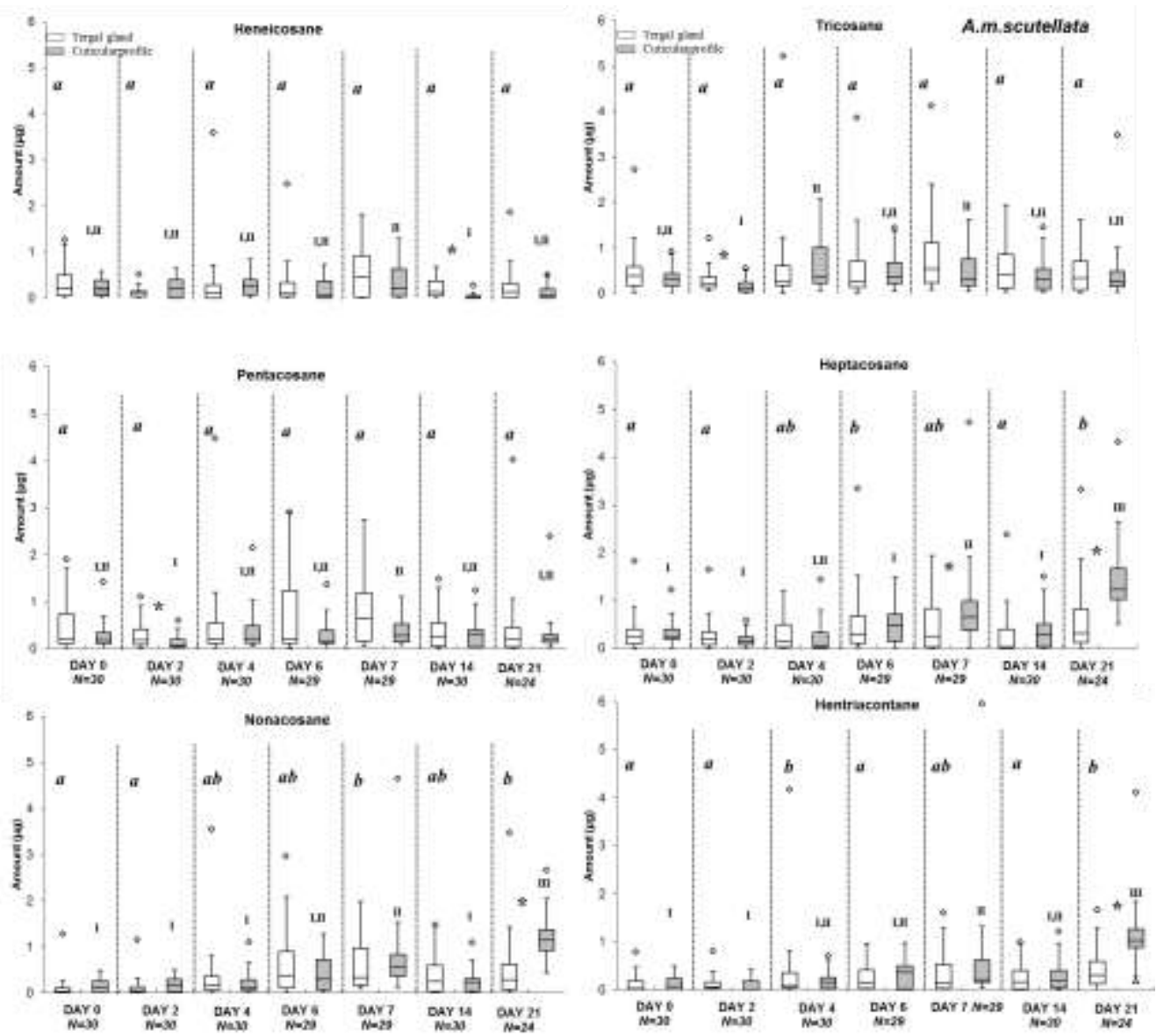

Figure 6. The amounts of $n$-alkanes in tergal gland and cuticular profiles of Apis $m$. scutellata workers (days 0 , $2,4,6,7,14$, and 21, $N=198$ ). The median line, quartile, whisker, mininAum and maxinßum outliers are shown. ${ }^{*}$ denotes significant difference at $P<0.05$ (Mann -Whitney $U$ test) of the pairwise comparison between tergal gland and cuticular profile for each day. Different letters within the row represent significant differences at $P<0.05$ (Kruskal Wallis-test) on different days for tergal gland profile. Different roman numerals within the row represent significant differences at $P<0.05$ (Kruskal Wallis-test) on different days for cuticular profile 

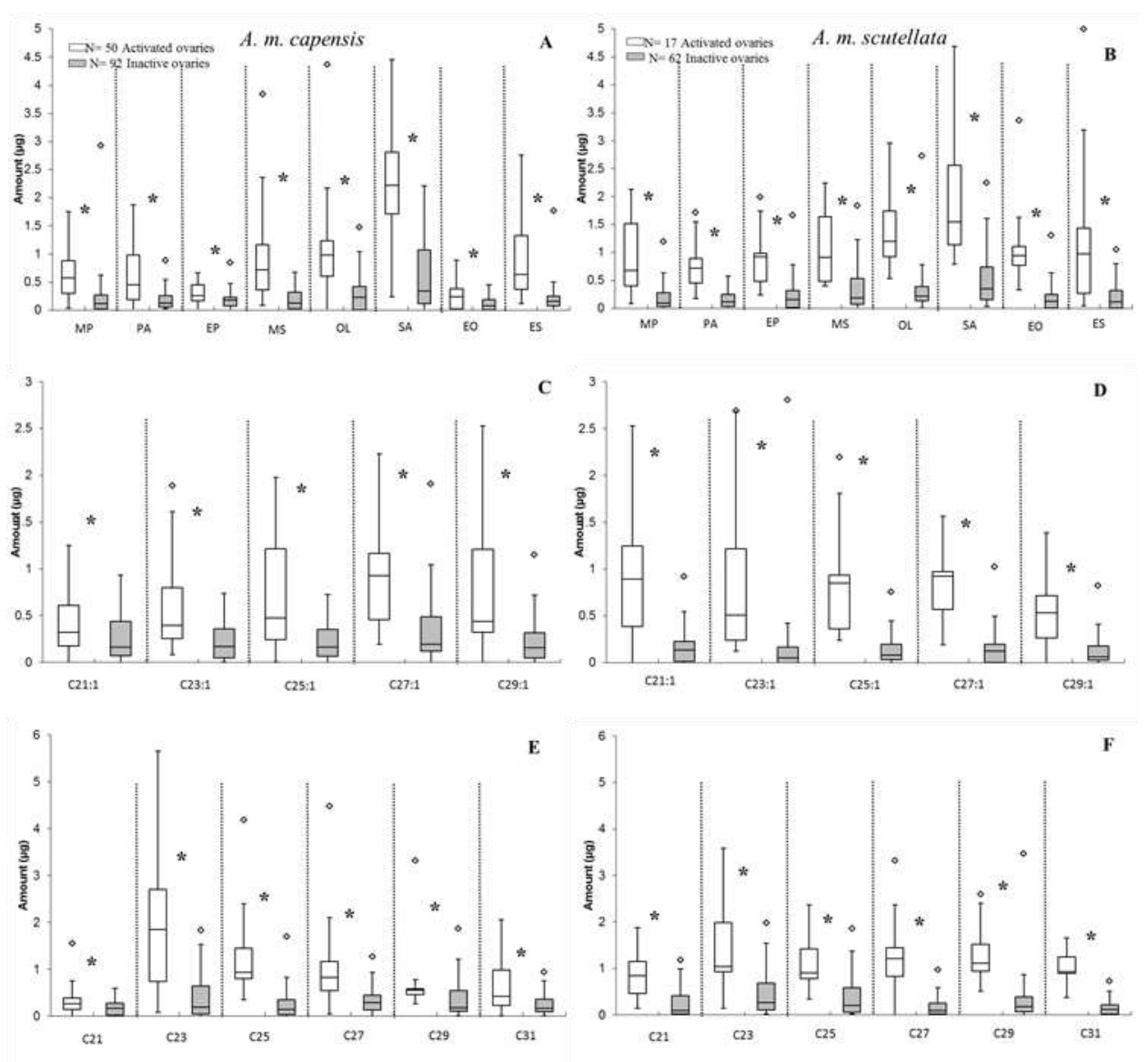

Figure 7. The amounts of compounds in tergal gland profiles of Apis m. capensis clones (days 4, 6, 7, 14, and $21, N=142$ ) and $A$. $m$. scutellata workers (days 7,14 , and $21, N=79$ ) with activated and inactive ovaries. Fatty acids and esters (Figs. A, B); unsaturated hydrocarbons (C, D) and saturated hydrocarbons (E, F) *denotes significant difference at $P<0.05$ (Mann -Whitney $U$ test) of the pairwise comparisg between workers with activated and inactive ovaries. The median line, quartile, whisker and the outliers are shown. MP= methyl palmitate; $\mathrm{PA}=$ palmitic acid; $\mathrm{EP}=$ Ethyl palmitate; $\mathrm{MS}=$ Methyl stearate; $\mathrm{OL}=$ Oleic acid; $\mathrm{SA}=$ Stearic acid; $\mathrm{EO}=$ Ethyl oleate; $\mathrm{ES}=$ Ethyl stearate; $\mathrm{C}_{21: 1}=$ Heneicosene; $\mathrm{C}_{23: 1}=$ Tricosene; $\mathrm{C}_{25: 1}=$ Pentacosene; $\mathrm{C}_{27: 1}=$ Heptacosene; $C_{29: 1}=$ Nonacosene; $C_{21}=$ Heneicosane; $C_{23}=$ Tricosane; $C_{25}=$ Pentacosane; $C_{27}=$ Heptacosane; $C_{29}=$ Nonacosane; $\mathrm{C}_{31}=$ Hentricontane 